\title{
Assessing core, e-learning, clinical and technology readiness to integrate telemedicine at public health facilities in Uganda: a health facility - based survey
}

Vincent Micheal Kiberu ${ }^{1 *+}$ (D), Richard E. Scott ${ }^{1,2,3+}$ and Maurice Mars ${ }^{1+}$

\begin{abstract}
Background: In developing countries like Uganda, there are shortages of health workers especially medical specialists. The referral process is frustrating to both patients and health workers (HWs). This is due to delays in accessing laboratory results/tests, costs of travel with resultant delay in consulting specialists. Telemedicine can help reduce these problems. To facilitate successful and sustainable telemedicine implementation the eHealth readiness of different stakeholders should be undertaken. This study was conducted at public health facilities (HFs) in Uganda to assess eHealth readiness across four domains; core, e-learning, clinical and technology, that might hamper adoption and integration of telemedicine.
\end{abstract}

Methods: A cross-sectional study using mixed methods for data collection was conducted at health center IVs, regional and national referral hospitals. The study was conducted in three parts. Quantitative data on core, e-learning and clinical readiness domains were collected from doctors and other healthcare providers (nurses/midwives, public health officers and allied healthcare workers). Respondents were categorised into 'aware and used telemedicine', 'aware and not used', 'unaware of telemedicine'. Focus Group Discussions were conducted with patients to further assess core readiness. Technology readiness was assessed using a questionnaire with purposively selected respondents; directors, heads of medical sections, and hospital managers/superintendents. Descriptive statistics and correlations were performed using Spearman's rank order test for relationship between technology readiness variables at the HFs.

Results: $70 \%$ of health professionals surveyed across three levels of HF were aware of telemedicine and $41 \%$ had used telemedicine. However, over 40\% of HWs at HC-IV and RRH were unaware of telemedicine. All doctors who had used telemedicine were impressed with it. Telemedicine users and non-users who were aware of telemedicine showed core, clinical, and learning readiness. Patients were aware of telemedicine but identified barriers to its use. A weak but positive correlation existed between the different variables in technology readiness.

Conclusion: Respondents who were aware of and used telemedicine across all HF levels indicated core, learning and clinical readiness for adoption and integration of telemedicine at the public HFs in Uganda, although patients noted potential barriers that might need attention. In terms of technology readiness, gaps still exit at the various HF levels.

Keywords: Telemedicine, Uganda, E-readiness, Health facilities

\footnotetext{
* Correspondence: vmicheal@yahoo.com

${ }^{\dagger}$ All authors contributed equally to this work.

'Department of TeleHealth, Nelson R. Mandela School of Medicine, University

of KwaZulu-Natal, Durban, South Africa

Full list of author information is available at the end of the article
}

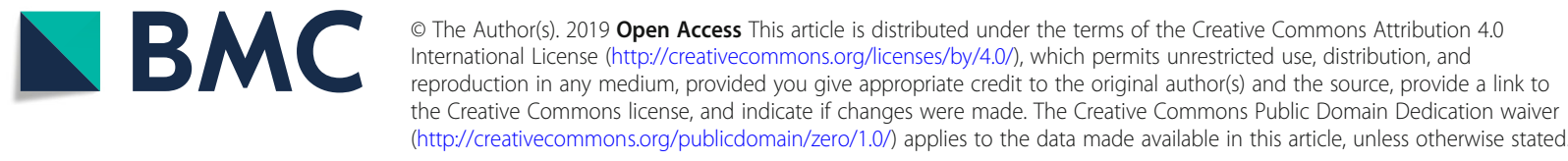




\section{Background}

Telemedicine is the remote delivery of clinical and other healthcare services using information and communications technologies (ICT). Health professionals in developed countries use telemedicine to broaden communication with patients and fellow professionals. Indeed, the American Telemedicine Association states "Telehealth has advanced from a curious form of clinical communication to a mainstay in the way providers and consumers interact" [1]. It is anticipated that telemedicine will have a more profound impact in developing countries than in developed countries [2] but successful implementation largely depends on the 'buy-in' of local people as recommended by Zilgalvis and Jungmann, [3, 4].

The World Health Organization (WHO) estimates the world will be short of 12.9 million healthcare workers (HWs) by 2035; today, that figure stands at 7.2 million. There is an extreme shortage of HWs in 57 countries, $63 \%$ of which are in sub-Saharan Africa [5]. Interventions like task shifting after training have been adopted but HWs in developing countries have continued to experience challenges in communication and consultation with peers [6]. In the African Region of the WHO, there are only 27 doctors per 100,000 people compared to 321 per 100,000 people in Europe [7]. The shortage of doctors and especially specialists is more acute in rural areas [8]. The referral process and subsequent consultation is frustrating for both patients and HWs due to long waiting times, delays accessing laboratory results, duplication of laboratory tests, the cost of travel, and the time taken to consult specialists [9]. Telemedicine can help address these problems by providing timely access to specialist and other healthcare, reducing the need and associated costs of travel, reducing consultation waiting time, and promoting home-based care [10].

eHealth readiness is defined as the "preparedness of healthcare institutions or communities for the anticipated change brought by programs related to information and communications technology" [11]. A lack of readiness has led to failure of eHealth implementations [12]. At least eight types of eHealth readiness have been described [13]. A recent review of eHealth readiness frameworks suggested a rank order of readiness themes based on the frequency of their occurrence in the literature analysed: Technological readiness, core/need/motivational readiness, acceptance and use readiness, organisational readiness, IT skills/training/learning readiness, engagement readiness, and societal readiness [14]. The lack of consistency in terms, content, and definitions applied suggests readiness aspects of importance to a specific setting must be considered. In this paper the focus is on four eHealth readiness domains of importance to Uganda: core, clinical, e-learning (electronic learning), and technology readiness.
Core readiness has been defined as the extent to which members of a community are dissatisfied with the current status of their healthcare service provision, see eHealth as a solution, and express their need and preparedness for eHealth services [13]. Clinical readiness refers to the readiness to provide clinical telemedicine services, as well as the ability to identify any gaps within an existing clinical telemedicine programme [15]. e-Learning means a mode of instruction intended to support learning, but delivered via a digital device such as a computer or mobile device, therefore, e-learning readiness refers to an institution's, or an individual's, readiness to adopt this mode of instruction and delivery [16].

Finally, regarding technology readiness, Rezai-Rad et al. [17] identified that this is associated with several components. These included the availability and affordability of ICT resources (e.g., hardware and software), quality of ICT infrastructure, use of networks, availability of ICT technical personnel, and IT security. However, a convenient definition has been provided by Mauco et al.: Technology readiness "gauges the availability and affordability of ICT resources necessary to implement a proposed eHealth innovation (e.g., skilled human resources, ICT support, quality ICT infrastructure, and power supply)" [13].

In Uganda, the National Healthcare System is a combination of the public and private sectors. The public sector is made up of all health facilities (HFs) owned by the government of Uganda, and supervised and regulated by the Ministry of Health. Other HFs include the health services of the Ministries of Defence, Education, Internal Affairs (the Police and Prisons), and Ministry of Local Government. The private health sector consists of private not-for-profit providers, private health practitioners, as well as traditional and complementary medicine practitioners. Provision of healthcare services by public HFs is decentralized at district and sub-district levels, each with a role in delivery and management of health services. The public healthcare system is structured into National Referral Hospitals (NRHs), Regional Referral Hospitals (RRHs), General Hospitals (GHs), and four levels of Health Centres (HC); HC-IV, HC-III, HC-II and Village Health Teams or HC-I.

There have been several initiatives by the Ugandan government to improve physical structure at district, regional and national referral HFs. However the healthcare system in Uganda still faces enormous challenges including insufficient technology resources, limited use of these resources (i.e. computers and Internet), and regular power blackouts. In addition, there are limited human resources (IT professionals) to provide technical support due to high staff turn-over and redeployment, a common occurrence in Uganda's health sector [18]. Despite this, the use of eHealth, and of ICT for communication in and between HFs in Uganda, has recently been documented $[19,20]$. 
For example, within the past 5-10 years, a variety of eHealth and telemedicine initiatives have been trialled. These include m-health tools such as WinSenga (a foetal heart rate monitor using a smart phone), Matibabu (a non-invasive malaria test), Text to Change (an SMS-based app to scale up HIV/AIDs awareness and promote HIV counselling and testing), a disease surveillance and medication tracking tool, a local EMR at an HIV/AIDs clinic, and videoconference-based exchanges with Universities in the USA for research, education and clinical practice [20]. However, no eHealth readiness assessment of core, clinical, e-learning or technology readiness has been conducted to assess challenges to telemedicine integration within Uganda's healthcare system. This may explain in part why several eHealth innovations that have been trialled have not gone beyond the proof of concept or pilot stage [20].

This study evaluated four eHealth readiness domains (core, clinical, e-learning and technology) that might hamper adoption and integration of telemedicine services at HFs in Uganda. Prior review of the literature on eHealth readiness assessment frameworks had revealed these four domains were critical in assessing eHealth readiness in developing countries. Study results will help mitigate any future barriers when implementing telemedicine technologies at HFs in Uganda, and potentially elsewhere.

\section{Methods}

This was a cross sectional study using mixed methods for data collection. Two semi-structured questionnaires were developed to collect quantitative data; first, for core, e-learning, and clinical readiness (Additional file 1 ), and second for technology readiness (Additional file 2). One health facility at the RRH and HC-IV levels was selected from each of three regions (Western, Northern and Eastern) using multi-stage random sampling. Mulago hospital, which functions as an HC-IV, GH and referral hospital for the Central region, was purposively identified for the study.

The technology readiness questionnaire was distributed to managers and physicians in-charge who were purposively selected. The core, e-learning, and clinical questionnaire was pre-tested for validity/consistency with $10 \mathrm{HWs}$ at a HC-IV in Mukono district in the Central region of Uganda. It was then distributed to doctors, nurses/midwives, public health officers (PHOs), and allied healthcare workers at the different facilities who were purposively selected. The first part of the questionnaire addressed awareness and / or use of telemedicine. Respondents were divided into three groups. The 'telemedicine user' group was further categorised into two sub-groups, doctors, and other health professionals and administrators. The other two groups included those who were not aware of telemedicine ('telemedicine naïve' group) and those who were aware of telemedicine but had not used it ('telemedicine aware' group). Each group was analysed to assess core, e-learning and clinical readiness to integration of telemedicine.

The four eHealth readiness domains were assessed in 17 questions, core (10), e-learning (3), clinical (3) and overall readiness (1). The 10 core questions were further divided into readiness to integrate telemedicine into practice (4), comfort with telemedicine (3) and process workflow (3). The questions were either dichotomous yes/no responses or used a 5-point Likert scale (strongly agree to strongly disagree). The results are presented as positive responses with the strongly agree and agree combined. Responses were compared using Fishers exact test with alpha set at $5 \%$. eHealth readiness was assessed based on quartiles of the average scores: $0-25 \%$ (no positive perception), $26-50 \%$ (a potentially positive perception requiring nurturing), 51-75\% (a generally positive perception that can be leveraged), and $76-100 \%$ (a favourably positive perception that can be leveraged).

To further assess core readiness, Focus Group Discussions (FGDs) were conducted with patients at Out-Patient Departments (OPD) at the identified HFs (Additional file 3). Convenience sampling was used to select the OPD patients, with patients invited by word of mouth to participate in the study. Each FGD comprised six to eight participants with seven FGDs conducted. Written notes were made of the discussions because participants had reservations about audio recording. Contemporaneous notes from the moderator and an assistant were used to ensure key points of the discussion and quotes were correctly and accurately documented. The discussions were summarised and data coded according to major themes, and sub-themes identified.

The technology readiness questionnaire was used to collect quantitative data on technology readiness from purposively selected participants (Additional file 4). These included directors, heads of medical sections, and hospital managers/superintendents. Descriptive statistics and correlations using Spearman's rank order test were performed. Alpha was set at $5 \%$.

\section{Results}

\section{Core, clinical and e-learning readiness Assessment}

In total, $406 \mathrm{HWs}$ responded to the core, clinical and e-learning readiness questionnaire (Table 1). The sample included more nurses and allied health workers than doctors.

Respondents' awareness of telemedicine and their use of telemedicine is shown in Table 2 . Only $30.3 \%$ of people had not heard of telemedicine (telemedicine naïve group), while $41.1 \%$ were 'telemedicine users', of whom significantly more doctors 74 (76.3\%) had used telemedicine than other health professionals $(p<0.0001)$. The remainder $(28.6 \%)$ constituted the 'telemedicine aware' group. 
Table 1 Demographic data of respondents by: health facility level, job category

\begin{tabular}{lllllll}
\hline & Nurses/ Midwives $n(\%)$ & Allied Health Workers $n(\%)$ & Public Health Officers $n(\%)$ & Doctors $n(\%)$ & Missing $n(\%)$ & Total N \\
\hline HC-IV & $39(43.8)$ & $24(27.0)$ & $22(24.7)$ & $4(4.5)$ & 0 & 89 \\
RRH & $55(31.6)$ & $45(25.9)$ & $29(16.7)$ & $44(25.3)$ & $1(0.6)$ & 174 \\
NRH & $22(15.3)$ & $46(32.2)$ & $26(18.2)$ & $49(34.3)$ & 0 & 143 \\
Total & $116(28.5)$ & $115(28.3)$ & $77(19.0)$ & $97(23.9)$ & $1(0.3)$ & 406 \\
\hline
\end{tabular}

The responses of doctors and other health professionals who have used telemedicine were further analysed according to several themes and subthemes identified in Table 3. A more detailed breakdown of these results by health facility is presented in Additional file 1.

Attitudes of those who had used telemedicine were positive. Over $90 \%$ of telemedicine users felt that it was cost effective, improved clinical outcomes and considered it was worth investing in telemedicine infrastructure. Over $75 \%$ felt telemedicine reduced referrals, changed the referral process, reduced hospital visits, addressed the shortage of health workers, and were happy to use it in place of traditional methods. It was also seen as a means of facilitating education with $91 \%$ feeling that health workers were ready to adopt e-learning. Significantly fewer doctors felt that it adversely affected the normal workflow $(p<0.01)$ and altered work practices $(p<0.05)$ than other telemedicine users. The need for eHealth policy, guidelines and training was identified by more than $90 \%$ of doctors.

Significant differences were noted between doctors and other users with respect to their overall impression of telemedicine, in terms of cost effectiveness, reducing hospital visits, solving the health worker shortage, its impact on normal workflow and work processes, and the worth of investment in telemedicine infrastructure.

Significantly, more 'telemedicine aware' respondents felt that it would reduce hospital visits, change the referral process, bridge the skills gap, and enhance e-learning than telemedicine users. Fewer felt that it adversely affected the normal process workflow, was worth investing in telemedicine infrastructure, and that health workers were ready for telemedicine. The 'telemedicine naïve' group were generally sceptical about the value of telemedicine, its use, and investing in it, although they were positive about e-learning and its use in bridging the skills gap.
The percentage of positive responses for each readiness domain was averaged for telemedicine users, telemedicine aware, and telemedicine naïve groups. Overall readiness was based on the single question about health workers' readiness to integrate telemedicine into practice (Fig. 1).

The user and aware groups averaged over $80 \%$ positive responses for all but process workflow, a domain in which low scores for changes to work flow and practice indicated a positive attitude to telemedicine. However, they expressed less overall readiness. Over $80 \%$ of both telemedicine users and aware groups were positive about core readiness, and over $80 \%$ of all respondents were positive about clinical and e-learning readiness. As expected, telemedicine users expressed the most overall readiness for telemedicine.

\section{Patients' perspective on Core readiness Awareness of telemedicine}

Participants from most of the FGDs, especially those at RRHs and NRHs, were aware of the concept of telemedicine. Some, particularly those at HC-IVs, said they had heard and were aware of the term 'telemedicine' but were not sure if they used it (telemedicine) at health facilities within their locale. In contrast those at higher health facility levels (RRH \& NRH) were generally aware of telemedicine services (email and telephone) and had used them to communicate with medical workers/ specialists:

"We are aware about telemedicine where a doctor treats a patient at a far distance using technology. Not sure though if this can work in our health centres because in most cases you need to see the doctor/ nurse and properly explain your sickness." (HC-IV patient).

Table 2 Awareness and use of telemedicine services

\begin{tabular}{lllll}
\hline Health Facility & Telemedicine Naïve Group $n(\%)$ & Aware of Telemedicine but not used it $\mathrm{n}(\%)$ & \multicolumn{3}{l}{ Aware of and used Telemedicine $\mathrm{n}(\%)$} \\
\cline { 4 - 5 } & & & Doctors & Others \\
\hline HC IV $(n=89)$ & $42(47.1)$ & $32(36)$ & $3(3.4)$ & $12(13.5)$ \\
RRH $(n=174)$ & $71(40.8)$ & $52(36.4)$ & $29(16.7)$ & $42(24.1)$ \\
NRH $(n=143)$ & $10(7.0)$ & $116(28.6)$ & $42(29.3)$ & $39(27.3)$ \\
Total $(n=406)$ & $123(30.3)$ & & $74(18.2)$ & $93(22.9)$ \\
\hline
\end{tabular}


Table 3 Analysis of doctors and others who have used telemedicine (TM)

\begin{tabular}{|c|c|c|c|c|c|c|}
\hline \multirow[t]{2}{*}{ Characteristics } & & \multicolumn{3}{|l|}{ TM Users } & \multicolumn{2}{|l|}{ Non-users } \\
\hline & & Doctors $(n=74)$ & Others $(n=93)$ & Total $(n=167)$ & $\begin{array}{l}\text { TM aware non-users } \\
(n=116)\end{array}$ & $\begin{array}{l}\text { Unaware of } \\
\text { TM }(n=123)\end{array}$ \\
\hline \multicolumn{7}{|l|}{$\begin{array}{l}\text { Core Readiness - Awareness of } \\
\text { Telemedicine }\end{array}$} \\
\hline \multirow[t]{7}{*}{ TM used for } & Diagnosis & $16(34.0)$ & $9(9.7)$ & $25(15.3)^{a}$ & - & - \\
\hline & Treatment & $23(31.1)$ & $14(15.2)$ & $37(22.7)^{a}$ & - & - \\
\hline & Prevention & $25(33.8)$ & $15(16.1)$ & $40(24.5)^{b}$ & - & - \\
\hline & e-Learning & $30(40.5)$ & $40(43.0)$ & $70(42.9)$ & - & - \\
\hline & Knowledge sharing & $21(28.4)$ & $31(33.3)$ & $52(31.9)$ & - & - \\
\hline & e-consultation & $47(63.5)$ & $46(49.5)$ & $93(57.1)$ & - & - \\
\hline & e-prescription & $60(81.1)$ & $1(1.1)$ & $61(37.4)^{c}$ & - & - \\
\hline Impressed with TM & & $74(100)$ & $81(87.1)$ & $155(95.1)^{c}$ & - & - \\
\hline \multicolumn{7}{|l|}{$\begin{array}{l}\text { Core Readiness - Integrating } \\
\text { Telemedicine }\end{array}$} \\
\hline TM reduces referrals & & $65(87.8)$ & $73(78.5)$ & $138(84.7)$ & $89(76.7)$ & $30(24.4)^{c}$ \\
\hline TM reduces hospital visits & & 65 (87.8) & $60(64.5)$ & $125(76.7)^{c}$ & $99(85.3)^{\mathrm{a}}$ & $52(42.3)^{c}$ \\
\hline Use TM over traditional methods & & $67(90.5)$ & $69(74.2)$ & $136(83.4)^{b}$ & $102(87.9)$ & $67(54.5)^{c}$ \\
\hline \multirow[t]{5}{*}{ Required before TM } & Licensing & $43(58.1)$ & $64(68.8)$ & $107(65.6)$ & $85(73.3)$ & $48(39.0)^{c}$ \\
\hline & Remuneration & $33(44.6)$ & $52(55.9)$ & $85(52.1)$ & $61(52.6)$ & $20(16.3)^{c}$ \\
\hline & Policy & $74(100)$ & $80(86.0)$ & $154(94.5)^{c}$ & $97(83.6)^{\mathrm{a}}$ & $58(47.2)^{c}$ \\
\hline & Training & $68(91.9)$ & $79(84.9)$ & $147(90.2)$ & $63(54.3)^{c}$ & $66(53.7)^{c}$ \\
\hline & Ethical Guideline & $69(93.2)$ & $61(65.6)$ & $130(79.8)^{c}$ & $66(56.9)^{c}$ & $45(36.6)^{c}$ \\
\hline TM solves HWs crisis & & $70(94.6)$ & $74(79.6)$ & $144(88.3)^{b}$ & $106(91.4)$ & $81(65.9)^{c}$ \\
\hline \multicolumn{7}{|l|}{$\begin{array}{l}\text { Core Readiness - Comfort with } \\
\text { Telemedicine }\end{array}$} \\
\hline TM is cost effective & & $59(79.7)$ & $93(100)$ & $152(93.3)^{c}$ & $98(84.5)$ & $85(69.1)^{c}$ \\
\hline Worth investing in TM infrastructure? & & $73(98.6)$ & $76(81.7)$ & $149(91.4)^{c}$ & $83(71.6)^{c}$ & $81(65.9)^{c}$ \\
\hline TM is effective for emergencies & & $66(89.2)$ & $86(92.5)$ & $152(93.3)$ & $111(95.7)$ & $96(78.0)^{b}$ \\
\hline \multicolumn{7}{|l|}{ Core Readiness - Process Workflow } \\
\hline TM affects normal process workflow & & $5(6.8)$ & $23(24.7)$ & $28(17.2)^{b}$ & $5(4.3)^{c}$ & $24(19.5)$ \\
\hline TM would alter work practices & & $24(32.4)$ & $47(50.5)$ & $71(43.6)^{a}$ & $54(46.6)$ & $44(35.8)$ \\
\hline TM would change referral process & & $63(85.1)$ & $66(71.0)$ & $129(79.1)^{\mathrm{a}}$ & $113(97.4)^{c}$ & $53(43.1)^{c}$ \\
\hline \multicolumn{7}{|l|}{$\begin{array}{l}\text { Learning Readiness - Enhancing Provider } \\
\text { Skill }\end{array}$} \\
\hline \multirow{5}{*}{$\begin{array}{l}\text { How do you access Continuing Medical } \\
\text { Education? }\end{array}$} & Conference & $71(95.9)$ & $65(69.9)$ & $136(83.4)^{c}$ & $91(78.4)$ & $70(60.3)^{c}$ \\
\hline & Internet & $70(94.6)$ & $56(60.2)$ & $126(77.3)^{c}$ & $83(71.6)$ & $45(38.8)^{c}$ \\
\hline & Workshop & $74(100)$ & $63(67.7)$ & $137(84.0)^{c}$ & $93(80.2)$ & $86(74.1)^{\mathrm{a}}$ \\
\hline & Attend course & $26(35.1)$ & $22(23.7)$ & $48(29.4)$ & $42(36.2)$ & $60(51.7)^{c}$ \\
\hline & Consult colleagues & $8(10.8)$ & $11(11.8)$ & $19(11.7)$ & $9(7.8)$ & $17(14.7)$ \\
\hline Could TM enhance e-learning? & & $62(83.8)$ & $62(66.7)$ & $124(76.1)^{a}$ & $114(98.3)^{c}$ & $113(91.9)^{c}$ \\
\hline Are HW ready to adopt e-learning? & & $68(91.9)$ & $81(87.1)$ & $149(91.4)$ & $107(92.2)$ & $113(91.9)$ \\
\hline Would TM use bridge skills gap? & & $49(66.2)$ & $78(83.9)$ & $127(77.9)^{\mathrm{b}}$ & $104(89.7)^{b}$ & $119(96.7)^{c}$ \\
\hline \multicolumn{7}{|l|}{ Clinical Readiness - Factors } \\
\hline Use of TM for clinical gaps & & $67(90.5)$ & $84(90.3)$ & $151(92.6)$ & $109(94.0)$ & $104(84.6)$ \\
\hline
\end{tabular}


Table 3 Analysis of doctors and others who have used telemedicine (TM) (Continued)

\begin{tabular}{|c|c|c|c|c|c|}
\hline \multirow[t]{2}{*}{ Characteristics } & \multicolumn{3}{|l|}{ TM Users } & \multicolumn{2}{|l|}{ Non-users } \\
\hline & Doctors $(n=74)$ & Others $(n=93)$ & Total $(n=167)$ & $\begin{array}{l}\text { TM aware non-users } \\
(n=116)\end{array}$ & $\begin{array}{l}\text { Unaware of } \\
\text { TM }(n=123)\end{array}$ \\
\hline Agree with treatment outcome & $70(94.6)$ & $85(91.4)$ & $155(95.1)$ & $111(95.7)$ & $99(80.5)^{b}$ \\
\hline TM will improve clinical outcome & $70(94.6)$ & $85(91.4)$ & $156(95.1)$ & $100(86.2)$ & $100(81.3)^{b}$ \\
\hline \multicolumn{6}{|l|}{ Overall Readiness } \\
\hline HW ready to integrate TM & $65(87.8)$ & $60(64.5)$ & $125(76.7)^{\mathrm{b}}$ & $68(58.6)^{b}$ & $64(52.0)^{c}$ \\
\hline
\end{tabular}

${ }^{a} \leq \mathbf{0 . 0 5},{ }^{b} \leq \mathbf{0 . 0 1},{ }^{\mathbf{c}} \leq \mathbf{0 . 0 0 1}$. Statistical comparison between doctors and others who use telemedicine is shown in the Telemedicine Total column, between users and those aware of telemedicine but not using it in Telemedicine Aware non-users column, and between telemedicine users and telemedicine naïve respondents in the Unaware of TM column

"In most cases you call and/or email your doctor to consult him/her about your health condition and s/he responds with certain prescriptions, advice .....we believe that's telemedicine! We have used it though at times don't realize it's actually the telemedicine."

(RRH patient).

"We know what telemedicine is all about but different telemedicine services like mobile phone for calling, WhatsApp and email may work well in our hospital setting. Services like video conferencing can be used with hospitals in developed countries."(NRH patient).

\section{Comfort using telemedicine}

Participants explained shortcomings they had experienced while using telemedicine to seek and/or receive healthcare within their hospital settings.

"Often times when you're feeling unwell, you just walk to the health centre to see the doctor/nurse for treatment. Although some cases you can always call to make an appointment with a specific clinician/doctor but in all you need to have physical interaction before you can receive treatment."(HC-IV patient).

"We have found it comforting and cost effective consulting and/or securing an appointment with the doctor. Experience has shown, what the doctor/ clinician does, is to recommend First Aid treatment but also advise you to visit the nearest health centre. But if it's a follow-up treatment the doctor may provide you with medical advice without necessarily asking you to come to the health centre." (RRH patient).

"There [are] those emergencies when you can't easily reach the health centre but only to call the doctor for the quickest solution. Such cases are possible if there's prior physical interaction with the doctor otherwise you will always be referred to the nearby health centre. It's not easy to explain your health details to a



Fig. 1 The average scores for core, clinical, e-learning and overall readiness of telemedicine users, telemedicine aware, and telemedicine naïve groups 
stranger unless if there is a formal arrangement with a health centre." (NRH patient).

\section{Integrating telemedicine}

Patients at all health facility levels were concerned about barriers to the integration of telemedicine within the public health sector in Uganda. Issues raised related to laboratory tests, prescriptions, records, and the cost of telemedicine.

\section{"When we use telemedicine to seek healthcare how then do we receive the drugs? How about if there's need for a blood test and to keep my patient's form? Those things (Telemedicine) can work well in developed countries." (HC-IV patient).}

"This might work for absentee/scarce health workers ... maybe reducing congestions at hospitals ... although challenges [exist] such as; heavy investment by government to train health workers, providing extra incentives, building the infrastructure, and subscribing to data and voice networks." (RRH patient).

\section{Technology readiness assessment}

Overall, 128 respondents completed the technology readiness questionnaire. Respondents were from one HC-IV and $\mathrm{RRH}$ from each of the three regions, plus the NRH. Only the District Health Office in one district responded to the questionnaire. The distribution of the respondents is shown in Table 4, and responses to the questionnaire in Table 5.

Despite moderate to high telemedicine knowledge, Technology Readiness at HC IVs was poor, and at some individual HC-IVs having an ICT budget, an ICT section, or access to ICT consultancy services did not equate to provision of any Internet related access and services. All RRHs were reported to have ICT budgets, an ICT section, and Internet access. Only one RRH in Western Region, had access to a web-portal, official email services, a network enabled for voice and data, anti-virus protection, and ICT security and therefore could be considered technology ready. The NRH was well provisioned with budget staff, services and security (Table 5).
Significant positive correlations were found between ICT equipment and budget, quality of service $(p=0.003)$, access to Internet connectivity $(p<0.001)$ and between ICT quality of service and access to network connectivity $(\mathrm{p}<0.001)$.

\section{Discussion}

The key findings of this study were that $70 \%$ of health professionals surveyed across three levels of HF were either aware of or had used (41\%) telemedicine. However, over $40 \%$ of HWs at HC-IV and RRH were telemedicine naïve. All doctors who had used telemedicine were impressed with it. 'Telemedicine user' and 'telemedicine aware' respondents showed core, clinical, and e-learning readiness for telemedicine. Patients were also generally aware of telemedicine but identified barriers to its use. For technology readiness, although all respondents reported knowledge about telemedicine, only the RRH in District 3 and the national referral hospital appeared to be technology ready for telemedicine. The quality of service, equipment and budget for ICT is still a challenge, especially at the lower HF levels.

Relatively few eHealth or telemedicine readiness studies have been conducted in the developing world. Whilst every country is different, with different health systems, burdens of disease, health needs, infrastructure and political agendas, the key findings of such studies are quite similar. For example, in Palestine mHealth approaches were regarded a promising strategy for mental health treatment interventions [21] while an assessment of telemedicine readiness at public health facilities in Addis Ababa, Ethiopia, showed a degree of readiness for telemedicine rating varied from a weak rating for technology readiness to strong rating for Organizational readiness [22].

It is generally acknowledged that eHealth readiness assessment should be undertaken before implementing an eHealth solution [23], in this case telemedicine. A recent review of eHealth readiness frameworks identified 13 papers covering eight readiness domains [13], whilst another systematic review of 63 papers identified 7 differently phrased eHealth readiness domains [14]. There is much confusion and inconsistency in the field of eHealth readiness assessment. No generic framework or underlying unified theory has been reported. Some frameworks address specific issues, with different target audiences assessed, in

Table 4 Demographic Data of the 128 Respondents by Health Facility level/Office, Job Title

\begin{tabular}{lllll}
\hline Job Title & HCIV & RRH & NRH & \\
\hline District Health Officials & 0 & 0 & 0 & DHO \\
Consultants & 0 & $20(42.6 \%)$ & $15(26.8 \%)$ & 0 \\
Heads of Section/ Units / Directors & $16(12.5 \%)$ & $27(57.4 \%)$ & $41(73.2 \%)$ & 0 \\
Hospital - In charge & $3(2.3 \%)$ & 0 & 0 & 0 \\
Total & $19(14.8 \%)$ & $47(36.7 \%)$ & $56(43.8 \%)$ & $6(4.7 \%)$ \\
\hline
\end{tabular}


Table 5 Summary statistics for the 128 respondents on technology readiness assessment

\begin{tabular}{|c|c|c|c|c|c|c|c|c|c|c|}
\hline \multirow[t]{2}{*}{ General Theme } & \multirow[t]{2}{*}{ Characteristics } & \multirow[t]{2}{*}{ Response } & \multicolumn{2}{|l|}{ District 1} & \multicolumn{2}{|l|}{ District 2} & \multicolumn{3}{|l|}{ District 3} & \multirow{2}{*}{$\begin{array}{l}\mathrm{NRH}(N=56 \\
-\end{array}$} \\
\hline & & & HC-IV $(n=7)$ & $\operatorname{RRH}(n=20)$ & HC-IV $(n=8)$ & $\operatorname{RRH}(n=15)$ & HC-IV $(n=4)$ & DHO's $(n=6)$ & $\operatorname{RRH}(n=12)$ & \\
\hline \multirow[t]{3}{*}{ General Question } & \multirow{3}{*}{$\begin{array}{l}\text { Knowledge about } \\
\text { TM }\end{array}$} & No & $3(42.9)$ & 0 & 0 & 0 & $1(25)$ & 0 & 0 & 0 \\
\hline & & Yes & $4(57.1)$ & $20(100)$ & $8(100)$ & $15(100)$ & $3(75)$ & $6(100)$ & $12(100)$ & $56(100)$ \\
\hline & & Missing & 0 & 0 & 0 & 0 & 0 & 0 & 0 & 0 \\
\hline \multirow{9}{*}{$\begin{array}{l}\text { ICT Technical } \\
\text { Personnel }\end{array}$} & \multirow{3}{*}{$\begin{array}{l}\text { Existence of ICT } \\
\text { section at the HF. }\end{array}$} & No & $6(85.7)$ & 0 & $8(100)$ & 0 & 0 & 0 & 0 & 0 \\
\hline & & Yes & 0 & $16(80)$ & 0 & $15(100)$ & $4(100)$ & 0 & $11(91.7)$ & $56(100)$ \\
\hline & & Missing & $1(14.3)$ & $4(20)$ & 0 & 0 & 0 & $6(100)$ & $1(8.3)$ & 0 \\
\hline & \multirow{3}{*}{$\begin{array}{l}\text { Access to ICT } \\
\text { Expert? }\end{array}$} & No & 0 & $14(70)$ & $8(100)$ & 0 & $4(100)$ & 0 & $8(66.7)$ & 0 \\
\hline & & Yes & $3(42.9)$ & 0 & 0 & $15(100)$ & 0 & 0 & 0 & $56(100)$ \\
\hline & & Missing & $4(57.1)$ & $6(30)$ & 0 & 0 & 0 & $6(100)$ & $4(33.3)$ & 0 \\
\hline & \multirow{3}{*}{$\begin{array}{l}\text { Access to ICT } \\
\text { consultancy services }\end{array}$} & No & 0 & $14(70)$ & $8(100)$ & 0 & $4(100)$ & 0 & $8(66.7)$ & 0 \\
\hline & & Yes & $3(42.9)$ & 0 & 0 & $15(100)$ & 0 & 0 & 0 & $56(100)$ \\
\hline & & Missing & $4(57.1)$ & $6(30)$ & 0 & 0 & 0 & $6(100)$ & $4(33.3)$ & 0 \\
\hline \multirow{3}{*}{$\begin{array}{l}\text { Existing ICT Equipment } \\
\text { \& Budget }\end{array}$} & \multirow{3}{*}{$\begin{array}{l}\text { Existence of ICT } \\
\text { Budget }\end{array}$} & No & $7(100)$ & 0 & 0 & 0 & $4(100)$ & 0 & 0 & 0 \\
\hline & & Yes & 0 & $16(80)$ & $8(100)$ & $15(100)$ & 0 & $6(100)$ & $12(100)$ & $42(75)$ \\
\hline & & Missing & 0 & $4(20)$ & 0 & 0 & 0 & 0 & 0 & $14(25)$ \\
\hline \multirow{4}{*}{$\begin{array}{l}\text { Access to Network } \\
\text { Connectivity }\end{array}$} & \multirow{3}{*}{$\begin{array}{l}\text { Access to Internet } \\
\text { Services }\end{array}$} & No & $7(100)$ & 0 & $8(100)$ & 0 & $4(100)$ & 0 & 0 & 0 \\
\hline & & Yes & 0 & $18(90)$ & 0 & $15(100)$ & 0 & $6(100)$ & $12(100)$ & $47(83.9)$ \\
\hline & & Missing & 0 & $2(10)$ & 0 & 0 & 0 & 0 & 0 & $9(16.1)$ \\
\hline & $\begin{array}{l}\text { Type of Internet } \\
\text { service }\end{array}$ & Wireless & 0 & $7(25)$ & 0 & $6(40)$ & 0 & $1(16.7)$ & $3(25)$ & $5(8.9)$ \\
\hline \multirow[t]{19}{*}{$\begin{array}{l}\text { Access to Network } \\
\text { Connectivity }\end{array}$} & & $\begin{array}{l}\text { Wireless, } \\
\text { Modem }\end{array}$ & 0 & $8(40)$ & 0 & $9(60)$ & 0 & 0 & $1(8.3)$ & $17(30.4)$ \\
\hline & & $\begin{array}{l}\text { Portable } \\
\text { Modem }\end{array}$ & 0 & $5(25)$ & 0 & 0 & 0 & $5(83.3)$ & $2(16.7)$ & $2(3.6)$ \\
\hline & & $\begin{array}{l}\text { Wireless, } \\
\text { LAN, Modem }\end{array}$ & 0 & 0 & 0 & 0 & 0 & 0 & 0 & $17(30.4)$ \\
\hline & & Missing & 0 & 0 & 0 & 0 & 0 & 0 & $6(50)$ & $15(26.8)$ \\
\hline & \multirow{3}{*}{$\begin{array}{l}\text { Does HF have a } \\
\text { web-portal }\end{array}$} & No & $7(100)$ & $18(90)$ & $8(100)$ & 0 & 0 & $5(83.3)$ & $12(100)$ & 0 \\
\hline & & Yes & 0 & 0 & 0 & $15(100)$ & 0 & 0 & 0 & $56(100)$ \\
\hline & & Missing & 0 & $2(10)$ & 0 & 0 & $4(100)$ & $1(16.7)$ & 0 & 0 \\
\hline & \multirow{3}{*}{$\begin{array}{l}\text { Is there use of } \\
\text { official e-Mail for } \\
\text { internal or external } \\
\text { communication? }\end{array}$} & No & $6(87.5)$ & $19(95)$ & $8(100)$ & 0 & $4(100)$ & $5(83.3)$ & $12(100)$ & 0 \\
\hline & & Yes & 0 & 0 & 0 & $15(100)$ & 0 & 0 & 0 & $56(100)$ \\
\hline & & Missing & $1(14.3)$ & $1(05)$ & 0 & 0 & 0 & $1(16.7)$ & 0 & 0 \\
\hline & \multirow{3}{*}{$\begin{array}{l}\text { Is the local network } \\
\text { enabled for both } \\
\text { voice and data? }\end{array}$} & No & $6(87.5)$ & $17(85)$ & $6(75)$ & 0 & $4(100)$ & $6(100)$ & $12(100)$ & 0 \\
\hline & & Yes & 0 & 0 & 0 & $15(100)$ & 0 & 0 & 0 & $41(73.2)$ \\
\hline & & Missing & $1(14.3)$ & $1(15)$ & $2(25)$ & 0 & 0 & 0 & 0 & $15(26.8)$ \\
\hline & \multirow{3}{*}{$\begin{array}{l}\text { Is licensed anti-virus } \\
\text { installed of the } \\
\text { computer? }\end{array}$} & No & $6(87.5)$ & $15(75)$ & $6(75)$ & 0 & $2(50)$ & $5(83.3)$ & $11(91.6)$ & $13(23.2)$ \\
\hline & & Yes & 0 & 0 & 0 & $14(93.3)$ & 0 & 0 & 0 & $36(64.3)$ \\
\hline & & Missing & $1(14.3)$ & $5(25)$ & $2(25)$ & $1(6.7)$ & $2(50)$ & $1(16.7)$ & $1(8.3)$ & $6(10.7)$ \\
\hline & \multirow{3}{*}{$\begin{array}{l}\text { Is there dedicated } \\
\text { IT personnel? }\end{array}$} & No & $5(71.4)$ & $18(90)$ & $8(100)$ & 0 & $4(100)$ & $5(83.3)$ & $12(100)$ & $32(57.1)$ \\
\hline & & Yes & 0 & 0 & 0 & $15(100)$ & 0 & 0 & 0 & 0 \\
\hline & & Missing & $2(28.6)$ & $2(10)$ & 0 & 0 & 0 & $1(16.7)$ & 0 & $24(42.9)$ \\
\hline
\end{tabular}

environments with different degrees of eHealth exposure and experience. Additionally, different tools have been used to score readiness assessment. The review noted that different survey tools will be needed for different groups such as managers, funders, technical staff, doctors, nurses and patients [13]. The tools will also have to differ depending on the proposed eHealth solution, with assessment of readiness for synchronous videoconference based telemedicine being different to that for deployment of a hospital information system.

In part, this study addressed some of these issues. The readiness of three sectors of stakeholders was assessed each using specific tools and methods: health workers at different levels of health facility; management, IT and 
technical experts; and patients. The large sample size of health workers surveyed (406 participants) provided unusual insight of readiness for telemedicine, primarily because three groups were identified based on their use and / or awareness of telemedicine (telemedicine user, telemedicine aware, and telemedicine naïve), and compared. The responses of those who were unaware of telemedicine prior to the survey (telemedicine naïve) are based solely on their perception, and can be likened to the opinions of participants in a Technology Acceptance Model (TAM) study; TAM refers to an information systems theory that models how users come to accept and use technology, based on their perception of its usefulness and ease of use [24]. The group aware of telemedicine but not using it (telemedicine aware) is also of interest. Although not specifically asked, their reasons for not using telemedicine or their failure to use telemedicine may reflect concerns over legal and regulatory issues, the quality of care provided by telemedicine, or may merely reflect lack of access to technology. Based on their responses the latter is most likely.

Patient readiness for telemedicine was unclear, since patients in this study seemingly equated telehealth to use of the mobile phone. Attempting to understand patient readiness is uncommon but important, because as availability increases it is likely patients, even the general population, will be primary users. Certainly in developed countries the importance of a citizen-centric focus, and empowering citizens as change agents, has been embraced (3). The insight gained from this study will facilitate the development of a tool for determining population readiness.

A recent eHealth readiness study in Mauritius found that $80 \%$ of respondents were aware of eHealth or had used telemedicine [25]. Khoja et al.'s eHealth readiness tool was used with managers and healthcare professionals already involved in an eHealth project [11]. In South Africa, the same tool was found to be problematic when used with district managers and hospital managers who were not involved in an eHealth project [26]. Saleh et al. [27], assessed health provider readiness on computer literacy, use, and access to computers at work in the Lebanon. Readiness for eHealth implementation was based on Holt's Readiness for Organizational Change scale (appropriateness, management support, change efficacy, personal beneficence [28] and showed that eHealth implementation is dependent on readiness of the health providers for change.

All groups (users, aware and naïve) showed a positive attitude for core readiness and integration of telemedicine. Process workflow has been defined as all activities related to patient care and can refer to clinical and administrative workflows and integrated IT solutions are considered critical to optimizing workflows in healthcare [29]. As noted earlier, the user and aware groups averaged over $80 \%$ positive responses for all but process workflow, a domain in which low scores for changes to work flow and practice indicate a positive attitude to telemedicine. The respondents showed readiness to integrate telemedicine at the HFs, especially among those who had used telemedicine in the delivery of healthcare.

Both telemedicine users and non-users showed clinical readiness for telemedicine integration at the public health facilities. Health workers see the potential benefits of telemedicine but do not yet have access to the infrastructure necessary to take advantage of it. The willingness to use ICT for health may reflect growing use of social media platforms and comfort with using computers and mobile phones.

This study has further demonstrated that e-learning is being used, and that the majority feel it would be of benefit and are ready to use it. These findings also align with the literature, which provides many examples of the use of e-learning to educate, train, or maintain the skills of the health and social care workforce in both developed (NHS eLearning; https://www.elearning.nhs.uk/), and developing countries [26,30].

While this study did not comprehensively survey all HF sites, the likelihood is that most facilities will not have adequate infrastructure. While many HWs were either aware of and / or using telemedicine, the HC-IVs lacked infrastructure and the RRH's lacked secure Internet and Web access for communication, prerequisites for both asynchronous (store and forward) and synchronous (real time) telemedicine. If the necessary technology and user training is not available, successful telemedicine cannot ensue. The introduction of 3G/4G networks offering unlimited Internet data packages [31] presents an opportunity for technology innovations for sites with limited connectivity and bandwidth.

The study also supported the literature which shows not only the need for eHealth readiness assessment, but the need for consistent terminology and description of a limited number of discrete readiness types, and the need for standardised tools for readiness assessment of different user groups (e.g., managers, funders, technical staff, doctors, nurses, patients, policy makers). Future research should focus on the latter two requirements.

Overall, the study findings can guide policy- and decision- makers in the health sector when designing, implementing, and scaling-up telemedicine services in Uganda and similar developing countries. It is recommended that eHealth readiness assessment be conducted for a specific intervention, and for specific groups in a particular healthcare setting using appropriate group specific readiness assessment tools, and not be generalised across all levels of HF. This will ensure evidence-based implementation and integration of telemedicine solutions relevant to the beneficiaries. 


\section{Strength and limitations}

A major strength for this paper is that eHealth readiness was addressed using the critical domains and sub-domains identified from the literature as relevant to the Ugandan and developing country context. In addition, this is believed to be the largest and most disparate sample surveyed regarding readiness. Thus the total sample size was 534 participants, and study participants were diverse (ranging from patients, nurses/midwives, district health teams, public health professionals, consultants, doctors and physicians in-charge). Also, both users and non-users of telemedicine services were included in the analysis to ascertain core, clinical and e-learning readiness to integration of telemedicine. Limitations of the study were that the readiness of the private healthcare sector has not been investigated and that respondents' perceptions of, and understanding of, telemedicine varied.

\section{Conclusion}

With regards to core, clinical and e-learning readiness for integration of telemedicine into public health facilities in Uganda, doctors across all health facility levels are typically more ready than other health professionals. This is particularly so for those who are aware of and have used telemedicine, highlighting the importance of knowledge of and exposure to telemedicine services. Unsurprisingly patients at the varying HF levels, especially the lower level HC-IVs, were sceptical and non-committal to integration of telemedicine, also perhaps because of lack of knowledge and exposure. Of practical concern is the fundamental technology gap in terms of necessary ICT equipment, which requires immediate attention prior to on-going attempts to integrate telemedicine services. This work provides a foundation for further studies on readiness in Uganda and other developing countries concerning implementation of other aspects of eHealth.

\section{Additional files}

Additional file 1: Appendix 1. Core, Clinical and eLearning Readiness Assessment Questionnaire. (DOC $66 \mathrm{~kb}$ )

Additional file 2: Appendix 2. Technology Readiness Assessment Questionnaire. (DOC 69 kb)

Additional file 3: Appendix 3. Focus Group Discussion Guide with patients. (DOC $30 \mathrm{~kb}$ )

Additional file 4: Appendix 4. Detailed breakdown of results by health facility. (DOC $91 \mathrm{~kb}$ )

\section{Abbreviations}

FGD: Focus Group Discussion; HC-IVs: Health Center Fours; HFs: Health Facilities; HWs: Health Workers; ICT: Information and Communications Technology; IT: Information Technology; NRH: National Referral Hospital; OPD: Out-Patient Department; RRH: Regional Referral Hospital; WHO: World Health Organization

Acknowledgements Not applicable.

\section{Funding}

Research reported in this publication was supported by the Fogarty International Center of the National Institutes of Health under Award Number D43TW007004. The content is solely the responsibility of the authors and does not necessarily represent the official views of the National Institutes of Health.

In addition, the funder did not have any attachment to the design of the study and collection, analysis, and interpretation of data and in writing the manuscript.

\section{Availability of data and materials}

The datasets used and/or analysed during the current study available from the corresponding author on reasonable request.

\section{Consent to use quotes}

Participants gave consent for direct quotes from their interviews/ questionnaires to be used in this manuscript.

\section{Authors' contributions}

VMK, MM and RES conceptualized the need to conduct this study. VMK collected data and VMK and MM analysed the data. VMK, MM \& RES conducted further data analysis and revised the paper. All authors read through and approved the paper for final submission.

\section{Ethics approval and consent to participate}

This study was approved by the Humanities and Social Science Ethics Committee of the University of KwaZulu-Natal and all participants gave written informed consent prior to responding to a questionnaire or participating in a focus group. In addition, further permission was granted by the Uganda's Ministry of Health and the respective District Health offices to conduct this study at the respective health units.

Consent for publication

Not applicable.

\section{Competing interests}

The authors declare that they have no competing interests.

\section{Publisher's Note}

Springer Nature remains neutral with regard to jurisdictional claims in published maps and institutional affiliations.

\section{Author details}

${ }^{1}$ Department of TeleHealth, Nelson R. Mandela School of Medicine, University of KwaZulu-Natal, Durban, South Africa. ${ }^{2}$ NT Consulting - Global e-Health Inc, Calgary, Alberta, Canada. ${ }^{3}$ University of Calgary, Calgary, Alberta, Canada.

Received: 26 April 2018 Accepted: 3 April 2019

Published online: 29 April 2019

\section{References}

1. American Telemedicine Association (ATA). Telehealth Basics. 2019. https:// www.americantelemed.org/resource/. Accessed 15 April 2019.

2. Hassibian MR, Hassibian S. Telemedicine acceptance and implementation in developing countries: benefits, categories, and barriers. Razavi Int J Med. 2016;4(3):e38332.

3. Zilgalvis PT, Jungmann S. From spectators to change agents: Empowering European citizens as drivers of e-health innovation. Working Paper No.2. 2015. https://www.politics.ox.ac.uk/publications/from-spectators-to-changeagents-empowering-european-citizens-as-drivers-of-e-health-innovation. html. Accessed 13 Nov 2018.

4. 18 Critical success factors for telemedicine deployment. Momentum. 2014. http://telemedicine-momentum.eu/18-factors/. Accessed 26 Mar 2018.

5. World Health Organization (WHO). Global health workforce shortage to reach 12.9 million in coming decades. Media Centre. 2013. http:/www.who.int/mediacentre/ news/releases/2013/health-workforce-shortage/en/. Accessed 20 Oct 2017.

6. Thu NTH, Wilson A, McDonald F. Motivation or demotivation of health workers providing maternal health services in rural areas in Vietnam: findings from a mixed-methods study. Hum Resour Health. 2015;13:91. 
7. African Health Observatory. Atlas of African Health Statistics 2016 - Health situation analysis of the African Region. 2016. http./apps.who.int/iris/bitstream/ handle/10665/206547/9789290232919.pdf?sequence=1. Accessed 13 Nov 2018.

8. Liu JX, Goryakin Y, Maeda A, Bruckner T, Scheffler R. Global health workforce labor market projections for 2030. Hum Resour Health. 2017;15:11.

9. Jang-Jaccard J, Nepal S, Alem L, Li J. Barriers for delivering telehealth in rural Australia: a review based on Australian trials and studies. Telemed E-Health. 2014;20(5):496-504.

10. Bradford NK, Caffery $\amalg$, Smith AC. Awareness, experiences and perceptions of telehealth in a rural Queensland community. BMC Health Serv Res. 2015; 15:427.

11. Khoja S, Scott RE, Casebeer AL, Mohsin M, Ishaq AF, Gilani S. E-health readiness assessment tools for healthcare institutions in developing countries. Telemed E-Health. 2007;13(4):425-31.

12. Khoja S, Scott R, Gilani S. E-health readiness assessment: promoting "hope" in the health-care institutions of Pakistan. World Hosp Health Serv. 2008;44(1):36-8.

13. Mauco KL, Scott RE, Mars M. Critical analysis of e-health readiness assessment frameworks: suitability for application in developing countries. J Telemed Telecare. 2018;24(2):110-7.

14. Yusif S, Hafeez-Baig A, Soar J. E-health readiness assessment factors and measuring tools: a systematic review. Int J Med Inform. 2017;107:56-64.

15. Clinical Site Readiness Assessment. Ontario telemedicine network. 2011. https://support.otn.ca/sites/default/files/clinical_site_readiness_assessment_ tool.pdf. Accessed 20 Dec 2017.

16. Rohayani AHH, Kurniabudi K, Sharipuddin S. A literature review: readiness factors to measuring e-learning readiness in higher education. Procedia Comput Sci. 2015;59:230-4.

17. Rezai-Rad M, Vaezi R, Nattagh F. E-health readiness assessment framework in Iran. Iran J Public Health. 2012;41(10):43-51.

18. Kiberu V, Matovu J, Makumbi F, Kyozira C, Mukooyo E, Wanyenze RK Strengthening district-based health reporting through the district health management information software system: the Ugandan experience. BMC Med Inform Decis. 2014;14:40

19. Omona W, Ikoja-Odongo R. Application of information and communication technology (ICT) in health information access and dissemination in Uganda. J Libr Inf Sci. 2006;38(1):45-55.

20. Kiberu VM, Mars M, Scott RE. Barriers and opportunities to implementation of sustainable e-health programmes in Uganda: a literature review. Afr J Prim Health Care Fam Med. 2017:9(1):a1277.

21. Ben-Zeev D, Fathy C, Jonathan G, Abuharb B, Brian RM, Kesbeh L, et al. mHealth for mental health in the Middle East: need, technology use, and readiness among Palestinians in the West Bank. Asian J Psychiatr. 2017;27:1-4.

22. Abera AA, Mengesha GH, Musa FP. Assessment of Ethiopian health facilities readiness for implementation of telemedicine. Commun Assoc Inf Syst. 2014;34:1209-34. https://doi.org/10.17705/1CAIS.03467.

23. Kgasi MR, Kalema BM. Assessment E-health readiness for rural south African areas. J Ind Intel Inform. 2014;2(2):131-5.

24. Holden RJ, Karsh B-T. The technology acceptance model: its past and its future in health care. J Biomed Inform. 2010;43(1):159-72.

25. Beebeejaun MR, Chittoo H. An assessment of e-health readiness in the public health sector of Mauritius. Int J Sci Basic Appl Res. 2017;35(1):193-210.

26. Chipps J, Brysiewicz P, Mars M. A systematic review of the effectiveness of videoconference-based tele-education for medical and nursing education. Worldv Evid-Based Nu. 2012;9(2):78-87.

27. Saleh S, Khodor R, Alameddine M, Baroud M. Readiness of healthcare providers for eHealth: the case from primary healthcare centers in Lebanon. BMC Health Serv Res. 2016;16(1):644.

28. Holt DT, Armenakis AA, Feild HS, Harris SG. Readiness for organizational change: the systematic development of a scale. J Appl Behav Sci. 2007:43(2):232-55.

29. Baine SO, Kasangaki A. A scoping study on task shifting; the case of Uganda. BMC Health Serv Res. 2014:14(1):184.

30. Mars M. Tele-education in South Africa. Front Public Health. 2014;2:173.

31. MTN Uganda finally launches unlimited data bundles: Here are the prices and speeds. Dignited. 2017. http://www.dignited.com/23572/mtn-ugandaunlimited-internet/. Accessed 20 Dec 2017.

Ready to submit your research? Choose BMC and benefit from:

- fast, convenient online submission

- thorough peer review by experienced researchers in your field

- rapid publication on acceptance

- support for research data, including large and complex data types

- gold Open Access which fosters wider collaboration and increased citations

- maximum visibility for your research: over $100 \mathrm{M}$ website views per year

At BMC, research is always in progress.

Learn more biomedcentral.com/submissions 